\title{
Role of Ventriculovascular Coupling in Cardiac Response to Increased Contractility in Closed-Chest Dogs
}

\author{
Gregory L. Freeman and James T. Colston \\ University of Texas Health Science Center at San Antonio, and Audie Murphy \\ Memorial Veterans Hospital, San Antonio, Texas 78284
}

\begin{abstract}
While both dobutamine and pacing tachycardia augment left ventricular (LV) contractility, whether overall cardiovascular response to these stimuli is comparable is not known. To address this question we studied seven dogs previously instrumented with three $L V$ diameter gauges and $L V$ pressure manometers. After ganglionic blockade and sedation, caval occlusions were performed at heart rates of 120,160 , and $200 \mathrm{bpm}$ before (C), and 160 and $200 \mathrm{bpm}$ after administration of 10 $\mu \mathrm{g} / \mathrm{kg}$ per min dobutamine, i.v. (D). The effective arterial elastance $\left(E_{\mathrm{a}}\right)$ went up from $14.2 \pm 4.5 \mathrm{mmHg} / \mathrm{ml}$ at $\mathrm{C120}$ to $19.6 \pm 8.8(P<0.025$ vs $C 120)$ and $24.2 \pm 10.4(P<0.001$ vs C120) $\mathrm{mmHg} / \mathrm{ml}$ at $\mathrm{C} 160$ and $C 200$. $E_{\text {es }}$, the slope of the end-systolic pressure-volume relation, increased with pacing from $9.7 \pm 4.6$ to $11.7 \pm 4.3(P<0.02)$, and $13.2 \pm 5.7(P<0.02)$ $\mathrm{mmHg} / \mathrm{ml}$ at 160 and $200 \mathrm{bpm}$. With dobutamine infusion $E_{\mathrm{a}}$ went down, and $E_{\text {es }}$ was further increased to $37.0 \pm 20.9$ $\mathrm{mmHg} / \mathrm{ml}$ at $160 \mathrm{bpm}(P<0.002$ vs $\mathrm{C160})$, and $53.0 \pm 22.6$ $\mathrm{mmHg} / \mathrm{ml}$ at $200 \mathrm{bpm}(P<0.002$ vs $\mathrm{C200})$. Comparison of stroke work and pressure-volume area from single beats with matched $L V$ end-diastolic volumes showed that these were both increased by dobutamine, but not by pacing tachycardia. While increased heart rate after dobutamine markedly increased contractility, $E_{a}$ was not changed, and neither stroke work nor pressure-volume was further increased. Thus, how well an increase in contractility is transmitted to the periphery is determined in part by arterial behavior. Assessment of both the arterial system and cardiac contractility is necessary to fully evaluate the overall impact of an inotropic stimulus. ( $J$. Clin. Invest. 1990. 86:1278-1284.) Key words: dobutamine • force-frequency effect $\bullet$ elastance $\bullet$ cardiac mechanics
\end{abstract}

\section{Introduction}

Under ordinary conditions in the intact heart, ventricular myocardium does not function at its maximal level of contractile performance. Thus the organism has reserves available, and contractility can be augmented when demand for cardiac performance is increased. Two mechanisms by which this can occur are adrenergic stimulation and increased heart rate, or

Address reprint requests to Dr. Gregory L. Freeman, University of Texas Health Science Center, Medicine/Cardiology, 7703 Floyd Curl Drive, San Antonio, TX 78284.

Received for publication 9 November 1990 and in revised form 20 February 1990

J. Clin. Invest.

(c) The American Society for Clinical Investigation, Inc.

$0021-9738 / 90 / 10 / 1278 / 07 \$ 2.00$

Volume 86, October 1990, 1278-1284
(1-3) and in intact hearts (4-6) have shown that both of these stimuli increase the inotropic state of the myocardium. How effectively this increase in myocardial performance is transmitted to the systemic circulation may be, however, determined to some extent by the vascular bed through the process of ventriculovascular coupling.

By analyzing hemodynamic data in the pressure-volume plane it is possible to gain information on the performance of both the left ventricle (LV) and the circulatory bed. For the LV, contractile performance has been characterized by means of the end-systolic pressure-volume $\left(P_{\text {es }}-V_{\text {es }}\right)$ relation (7), as well as the relation between stroke work (SW) and LV end-diastolic volume $(8,9)$. As an extension of the $P_{\text {es }}-V_{\text {es }}$ relation, Suga and colleagues have shown in isolated supported hearts that the area bounded by the $P_{\text {es }}-V_{\text {es }}$ relation and the pressure-volume loop, which they term the pressure-volume area (PVA), is linearly related to myocardial oxygen consumption $(10,11)$. These investigators have also shown in intact dogs that the fraction of the PVA comprised of stroke work is an index of the efficiency of mechanical transfer from the LV to the circulatory bed (12). Thus, the pressure-volume plane allows evaluation of the performance of the muscle (contractility) as well as the LV as a pump supplying output to the systemic circulation.

Pressure-volume plane analysis is also useful for assessment of the mechanical behavior of the circulatory bed. Sunagawa and colleagues have shown that effective arterial elastance $\left(E_{\mathrm{a}}\right)$ can be estimated from the LV pressure-volume loop $(13,14)$. This parameter allows a measure of how much the aortic pressure will rise for a given degree of cardiac ejection. Since the pressure-volume construct provides data on both LV performance and circulatory performance it may be ideal for assessing ventriculovascular responses to stimuli in the intact circulation.

The purpose of this study was to evaluate changes of LV contractility and ventriculovascular coupling that occur in intact, closed-chest dogs after inotropic stimulation by increased stimulation frequency, before and after dobutamine infusion. The results demonstrate that these stimuli have additive effects on LV contractility. The overall circulatory response to each stimulus differed considerably because of different effects on $E_{\mathrm{a}}$. In particular, the increase in contractility due to tachycardia was only partly transmitted to the arterial circulation because of the accompanying arterial response. Thus, in addition to how stimuli affect the heart, their effects on the vascular system should be considered when assessing how they alter overall cardiovascular behavior.

\section{Glossary \\ C control \\ D dobutamine}




$\begin{array}{ll}D_{\mathrm{AP}} & \text { anterior-posterior LV diameter } \\ D_{\mathrm{LA}} & \text { long axis LV diameter } \\ D_{\mathrm{SL}} & \text { septal-lateral LV diameter } \\ \mathrm{d} P / \mathrm{d} t & \text { rate of change of pressure with respect to time } \\ E_{\mathrm{a}} & \text { effective arterial elastance } \\ E_{\mathrm{es}} & \text { slope of the end-systolic pressure-volume relation } \\ \mathrm{EDV} & \text { end-diastolic volume } \\ \mathrm{LV} & \text { left ventricular } \\ M_{\mathrm{w}} & \text { slope of the stroke work end-diastolic volume relation } \\ \mathrm{PVA} & \text { pressure-volume area } \\ \text { SW } & \text { stroke work } \\ \text { TransPVA } & \text { percentage of PVA transferred to the circulatory bed }\end{array}$

\section{Methods}

All studies were carried out according to the NIH Guide for the Care and Use of Laboratory Animals (15). Seven conditioned mongrel dogs of either sex were used. Our surgical preparation has been previously described in detail $(16,17)$. In brief, after administration of $1-2 \%$ halothane anesthesia and under sterile conditions, three sets of piezoelectric crystals were implanted in the endocardium of the LV. These permitted continuous assessment of anterior-posterior $\left(D_{\mathrm{AP}}\right)$, septallateral $\left(D_{\mathrm{SL}}\right)$, and long axis $\left(D_{\mathrm{LA}}\right)$ diameters. A micromanometer (Konigsberg Instruments, Inc., Pasadena, CA) and a 1.1-mm i.d. fluid-filled catheter for calibration of the micromanometer were placed through the LV apex and held in place by a purse-string suture. Pacing electrodes were sewn to the epicardium of the left atrium. Balloon occluder cuffs were positioned around both the superior and inferior venae cavae, and the chest was closed in multiple layers, with leads exiting from the base of the neck. The animals were studied after full recovery from surgery, a period of at least $10 \mathrm{~d}$, during which time they were trained to lie quietly in a sling.

Each dog was studied while lying on its side after sedation with intravenous fentanyl $(0.03-0.06 \mathrm{mg} / \mathrm{kg})$ in combination with droperidol $(1.5-3.0 \mathrm{mg} / \mathrm{kg}$ ) and after intubation. Autonomic blockade was produced by the intravenous administration of hexamethonium $(20-25 \mathrm{mg} / \mathrm{kg})$.

To minimize the influence of fluctuations in intrathoracic pressure, data were recorded over 10-s-periods while the dogs were apneic after a brief period of hyperventilation. During the recording period, the endotracheal tube was held open to the atmosphere and the dogs were observed to make certain they made no respiratory efforts. Steady state data were recorded after atrial pacing to a rate of $120 \mathrm{bpm}(\mathrm{Cl} 20)$, then caval occlusions were performed to reduce $\mathrm{LV}$ pressure and volume. Next, the pacing rate was increased to $160 \mathrm{bpm}(\mathrm{C160})$ and steady state and caval occlusion data again recorded; this was repeated after heart rate was increased to $200 \mathrm{bpm}$ (C200).

At this point dobutamine infusion was begun at a rate of $10 \mu \mathrm{g} / \mathrm{kg}$ per min. After a 5-10 min equilibration time data were again recorded at atrial pacing rates of $160 \mathrm{bpm}$ (D160) and $200 \mathrm{bpm}$ (D200).

Analogue recordings were made on an 8-channel, forced ink oscillograph (Beckman Instruments'inc., Palo Alto, CA) at a paper speed of $25 \mathrm{~mm}$ per $\mathrm{s}$. The following measurements were obtained: $L V$ pressure $(P)$, the first derivative of LVP with respect to time $(\mathrm{d} P / \mathrm{d} t), \mathrm{ECG}$, and the three dimensions $D_{\mathrm{AP}}, D_{\mathrm{SL}}$, and $D_{\mathrm{LA}}$. These parameters were also simultaneously converted from analogue to digital at a sampling rate of $200 \mathrm{~Hz}$ using a PC (IBM Corp., Danbury, CT), and stored on floppy disks.

Data analysis. The digitized data were analyzed using computer algorithms developed in our laboratory. Pressure and diameter data were analyzed without the use of digital filters. $\mathrm{d} P / \mathrm{d} t$ was calculated using a running 5-point linear fit of the $\mathrm{LV}$ pressure values. LV volume was calculated from the three orthogonal diameters, assuming the ventricle was an ellipsoid, using the equation: $V_{\mathrm{LV}}$ $=\pi / 6\left(D_{\mathrm{AP}} \cdot D_{\mathrm{SL}} \cdot D_{\mathrm{LA}}\right)$. End-diastole was defined at the $z$ point of the $\mathrm{LV}$ pressure curve, which is the pressure nadir after atrial systole, prior to the rapid rise in $\mathrm{LV}$ pressure. End-systole was considered to occur at the left upper corner of the $\mathrm{LV}$ pressure-volume loop (18). The volume at the onset of ejection $\left(V_{\mathrm{ej}}\right)$ was defined as the right upper corner of the LV pressure-volume loop. Stroke volume (SVOL) was defined as $V_{\mathrm{ej}}-$ $V_{\text {es. }}$. Stroke work $(\mathrm{SW})$ was defined as the area of the LV pressurevolume loop for each cardiac cycle, described by the equation: SW $=\int P \mathrm{~d} V$.

The $P_{\text {es }}-V_{\text {es }}$ relation data were fit applying a linear least-squares algorithm to the equation: $P_{\mathrm{es}}=E_{\mathrm{es}}\left(V_{\mathrm{es}}-V_{0}\right)$, where $E_{\mathrm{es}}$ is the slope of the relation, and $V_{0}$ its volume axis intercept. To avoid problems that could arise from extrapolation of the $P_{\mathrm{es}}-V_{\mathrm{es}}$ relation substantially beyond the data range, the volume at an end-systolic pressure of 100 $\mathrm{mmHg}$, termed $V_{100}$, was determined from the coefficients defining the linear relation.

The slope and volume axis intercepts of the SW-EDV relation were determined by linear least-squares algorithm using the equation: SW $=M_{\mathrm{w}}\left(\mathrm{EDV}-V_{\mathrm{w}}\right)$, where $M_{\mathrm{w}}$ is the slope of the relation, and $V_{\mathrm{w}}$ its volume intercept. Again, to avoid errors which could arise from extrapolating beyond the data range, end-diastolic volume at SW of $1,000 \mathrm{mmHg}-\mathrm{ml}$ was determined from the linear coefficients, and termed $V_{\text {w1000 }}$.

The PVA was defined as described by Suga et al. (10), and was calculated for each beat of a caval occlusion run. The efficiency of energy transfer from PVA to external mechanical work was evaluated following the method of Nozawa et al. (12), using the equation: $\mathrm{Trans}_{\mathrm{PVA}}=(\mathrm{SW} / \mathrm{PVA}) \cdot 100$, where Trans $\mathrm{PVA}_{\mathrm{A}}$ represents the percentage of the PVA transferred to the circulatory bed.

To avoid confusion which could arise due to interactive effects of changes in both slope and intercept values, the data set was analyzed in a second fashion. For each dog, heart beats with closely matched LVEDV (within $1 \mathrm{ml}$ ) were chosen from the five caval occlusion runs. Since the relation between SW and LV end-diastolic volume is linear (8), comparison of single beat SW and PVA at matched EDV allows assessment of how the heart responded to increased heart rate before and after dobutamine infusion. Also, $\mathrm{d} P / \mathrm{d} t_{\max }$ at matched LVEDV was compared, since it has been shown (19) that these parameters are related in a linear fashion.

Effective arterial elastance was defined following the approach of Sunagawa (13), as $P_{\mathrm{es}} / \mathrm{SVOL}$. For each run, $E_{\mathrm{a}}$ was determined from the first beat of the caval occlusion, before changes from steady state had occurred.

Statistical analysis. Data are presented as mean \pm 1 SD. The accuracy of the linear fits for the three constructs were assessed by the Pearson correlation coefficient. Comparisons under the five sets of test conditions were made by repeated measures ANOVA, and when differences were found they were evaluated by the Student-NewmanKeuls test. The level of significance was taken as $P<0.05$.

\section{Results}

Effects of pacing and dobutamine on myocardial performance. Typical analogue recordings under the five test conditions from one dog are shown in Fig. 1. The results of the caval occlusion runs and for $\mathrm{d} P / \mathrm{d} t_{\max }$ at matched LVEDV are shown in Table I. Results for $E_{\mathrm{es}}$ and $M_{\mathrm{w}}$ are shown in Fig. 2. The correlation coefficients for the $P_{\text {es }}-V_{\text {es }}$ regressions averaged 0.989 , ranging from 0.904 to 0.999 . For the SW-EDV relation the average value was 0.989 , with a range from 0.866 to 0.999 . As previously shown in our lab (6), increased heart rate caused a monotonic increase in contractility, as reflected by $E_{\mathrm{es}} . E_{\mathrm{es}}$ was progressively larger with each increase in rate before the administration of dobutamine; the addition of dobutamine caused a further marked increase of contractility. The value of $E_{\mathrm{es}}$ for D160 was greater than that for C160 (P $<0.002$ ), and the value for D200 was greater than that for $\mathrm{C} 200(P<0.002)$. Also, the contractile response to pacing and 


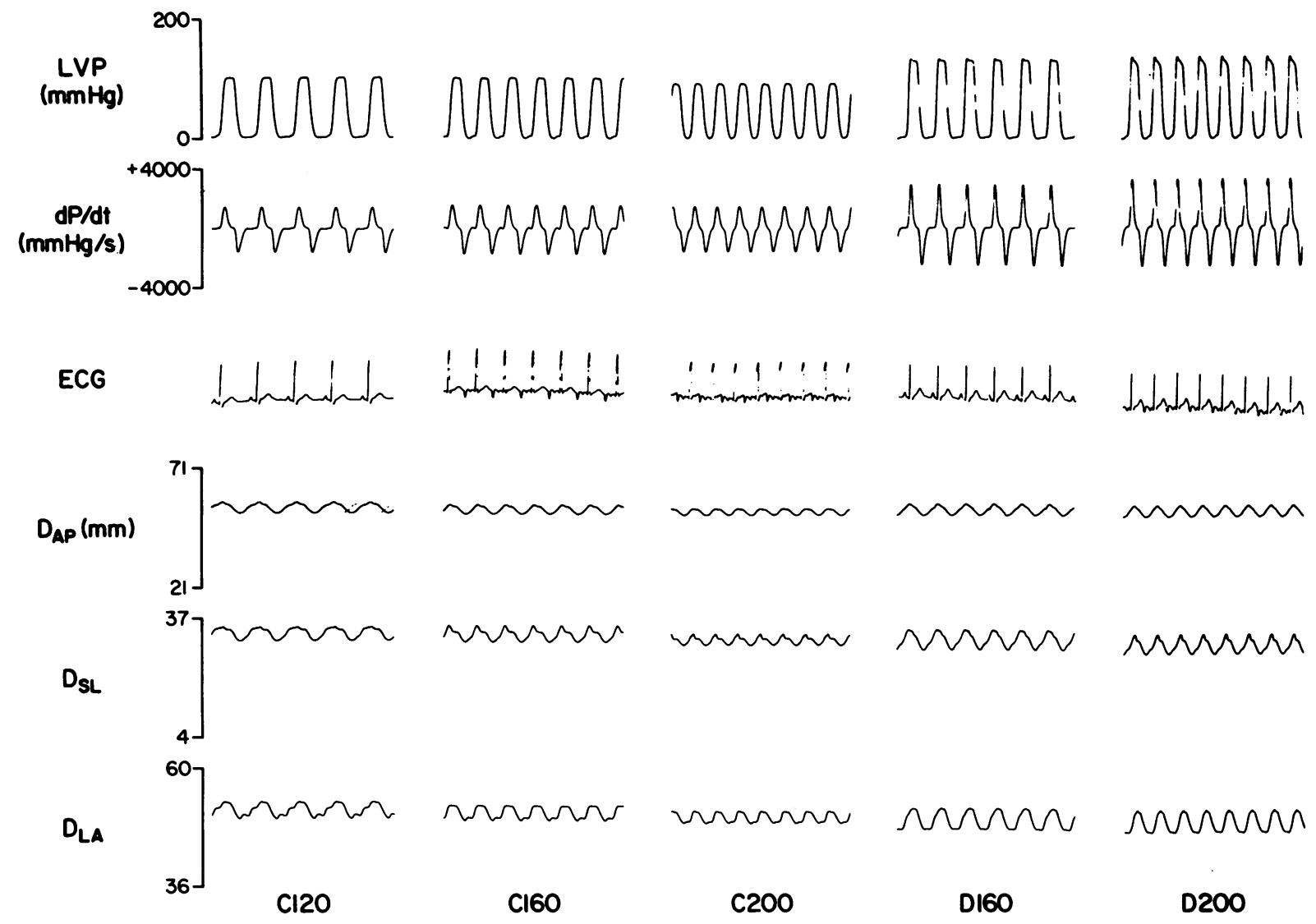

Figure 1. Analogue tracings recorded during each of the test conditions. LVP, left ventricular pressure; $\mathrm{d} P / \mathrm{d} t$, rate of change of pressure with respect to time; $D_{\mathrm{AP}}$, anterior-posterior $\mathrm{LV}$ diameter; $D_{\mathrm{SL}}$, septal-lateral $\mathrm{LV}$ diameter; $D_{\mathrm{LA}}$, long axis $\mathrm{LV}$ diameter.

dobutamine appeared to be additive, since $E_{\mathrm{es}}$ was larger for D200 than it was for D160 $(P<0.01)$.

The values for $V_{100}$ demonstrate that this parameter was very similar at different heart rates before addition of dobutamine, but was smaller at both rates after the addition of dobutamine. Thus, not only does the relation have a steeper slope at any given heart rate after the addition of dobutamine, but it also is shifted to the left in the range of pressures measured in the experiment. Increased heart rate after dobutamine infusion does not further shift the relation to the left.

The $\mathrm{d} P / \mathrm{d} t_{\max }$ data show that before dobutamine infusion $\mathrm{d} P / \mathrm{d} t_{\max }$ tended to increase with increased rate; these differences were not statistically significant. Dobutamine increased $\mathrm{d} P / \mathrm{d} t_{\max }$ at both heart rates tested, and the values for D200 were significantly greater than those of D160 $(P<0.01)$, suggesting an additive effect of heart rate and dobutamine on this parameter.

Unlike the other indexes of contractility, $M_{\mathrm{w}}$ decreased as heart rate increased. The value at $\mathrm{C} 200$ was lower than the values at either $\mathrm{C1} 20$ or $\mathrm{C160}(P<0.01$ and $P<0.002$, respectively). The value at D160 was lower than any of the control runs, and was not further reduced by pacing to a rate of 200 . $V_{\text {w1000 }}$ was higher at C200 when compared to either $\mathrm{C} 120$ or C160 ( $P>0.02$ for both comparisons). Thus, under control conditions increasing heart rate moved this relationship to the right, indicating reduced performance in terms of stroke work, or work done ejecting blood into the circulatory bed. $V_{\text {w1000 }}$ was smaller at both D160 and D200 when compared to all of the heart rates under control conditions $(P \leq 0.02$ for all comparisons). This indicates that dobutamine, unlike pacing tachycardia, increased performance in terms of stroke work.

Table I. Contractility Data

\begin{tabular}{|c|c|c|c|c|c|c|}
\hline HR & & $E_{\mathrm{es}}$ & $V_{100}$ & $\mathrm{~d} P / \mathrm{d} t_{\max }$ & $\boldsymbol{M}_{\mathbf{w}}$ & $V_{\mathrm{w}_{1000}}$ \\
\hline \multirow{2}{*}{$\mathrm{C} 120$} & Mean & 9.7 & 22.9 & 1503 & 55.9 & 34.7 \\
\hline & SD & 4.6 & 9.6 & 272 & 8.8 & 9.0 \\
\hline \multirow{2}{*}{$\mathrm{C} 160$} & Mean & $11.7^{*}$ & 22.6 & 1534 & 52.3 & 36.6 \\
\hline & SD & 4.6 & 9.8 & 352 & 4.7 & 9.1 \\
\hline \multirow[t]{2}{*}{ C200 } & Mean & $13.2^{\ddagger}$ & 23.0 & 1593 & $45.7^{* \neq}$ & 40.8 \\
\hline & SD & 5.7 & 9.7 & 337 & 9.8 & 9.7 \\
\hline \multirow[t]{2}{*}{ D160 } & Mean & $37.0^{\S}$ & $14.9^{\S}$ & $3014^{8}$ & $83.9^{8}$ & $27.7^{\S}$ \\
\hline & SD & 20.9 & 4.5 & 818 & 12.3 & 6.6 \\
\hline \multirow[t]{2}{*}{ D200 } & Mean & $53.0^{\mid 1 / 1}$ & $14.6^{\prime \prime}$ & $3853^{\mid 119}$ & $83.1^{11}$ & $27.4^{\prime \prime}$ \\
\hline & SD & 22.6 & 4.3 & 1197 & 24.2 & 5.6 \\
\hline
\end{tabular}

$E_{\text {es }}$, slope of the $P_{\text {es }}-V_{\text {es }}$ relation, $\mathrm{mmHg} / \mathrm{ml} ; V_{100}$, volume intercept of the $P_{\text {es }}-V_{\text {es }}$ relation at $100 \mathrm{mmHg}, \mathrm{ml} ; \mathrm{d} P / \mathrm{d} t_{\max }$, maximal rate of change of $L V$ pressure, $\mathrm{mmHg} / \mathrm{s} ; M_{\mathrm{w}}$, slope of the SW-EDV relation, $\mathrm{mmHg}-\mathrm{ml} / \mathrm{ml} ; V_{\mathrm{w}_{1000}}$, volume intercept of the SW-EDV relation at $1,000 \mathrm{mmHg}-\mathrm{ml}$.

$* P<0.02$ vs $\mathrm{C} 120$.

${ }^{\ddagger} P<0.02$ vs $\mathrm{C} 160$.

$\S P<0.002$ vs $\mathrm{C} 160$.

" $P<0.002$ vs $C 200$.

' $P<0.01$ vs D160. 

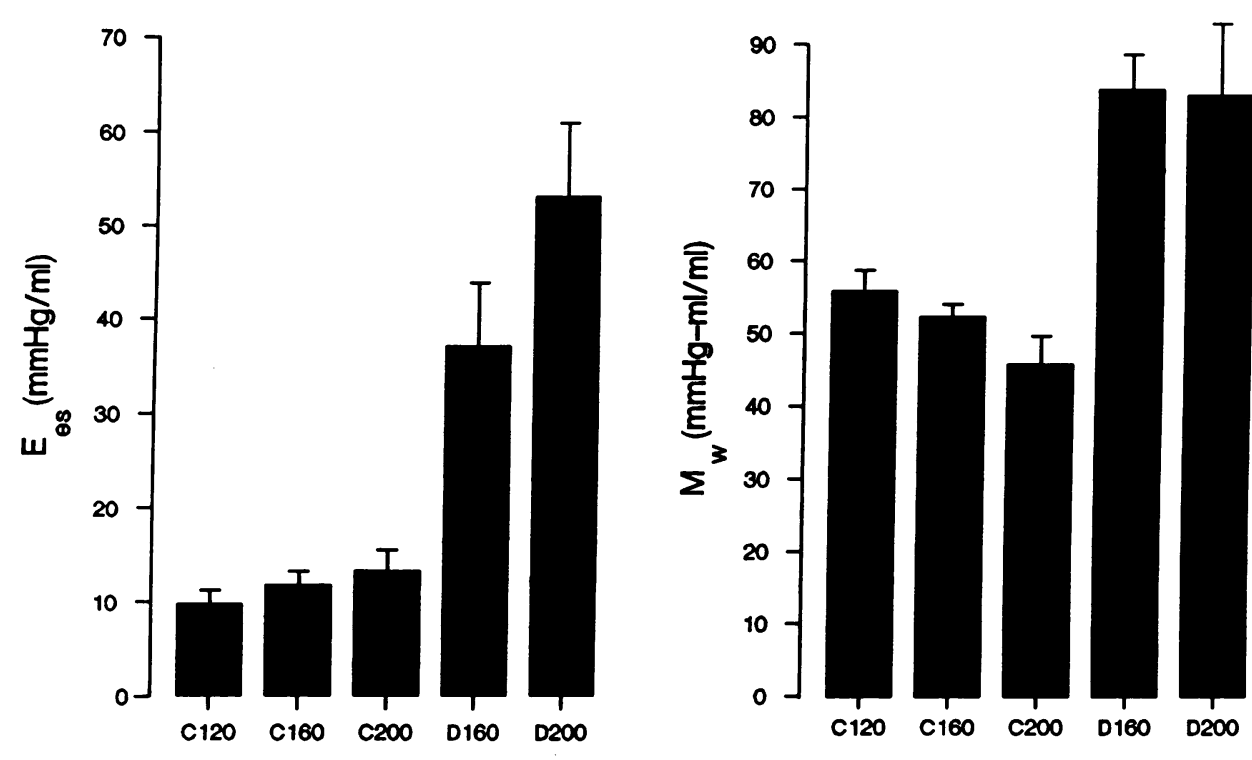

Figure 2. The effect of increases in heart rate before and after dobutamine on $E_{e s}$, the slope of the end-systolic pressure-volume relation, and $M_{\mathrm{w}}$, the slope of the stroke work enddiastolic volume relation. The bars are 1 SEM.

Effects of dobutamine and pacing on LV chamber performance. The values for PVA, SW, and Transpva under the five test conditions are shown in Table II. Single beats with closely matched LVEDP were chosen from runs under the different conditions in each dog. SW from a given LVEDV was progressively reduced by increasing heart rate: the value at $\mathrm{C} 160$ was smaller than that at $\mathrm{C} 120(P<0.004)$, and fell further at $\mathrm{C} 200$ $(P<0.002$ vs $C 160)$. Stroke work was increased at any heart rate by dobutamine infusion $(P<0.002$ for comparisons at 160 and $200 \mathrm{bpm}$ ). Also, increasing heart rate during dobutamine infusion led to an increase in SW $(P<0.02)$, as opposed to the decrease in SW that occurred with increased heart rate under control conditions.

The PVA from a given LVEDV also decreased with increased heart rate under control conditions. The values for C160 and C200 were both lower than those for C120 ( $P$ $<0.004)$. PVA was, however, increased at any heart rate dur-

Table II. Data from Beats with Matched LVEDV

\begin{tabular}{lllllc}
\hline & & LVEDV & SW & PVA & TranspvA \\
\hline C120 & Mean & 23.4 & 357 & 745 & 49.3 \\
& SD & 11.9 & 226 & 472 & 7.8 \\
C160 & Mean & 23.2 & $302^{*}$ & $599^{*}$ & 50.1 \\
& SD & 12.2 & 208 & 382 & 8.6 \\
C200 & Mean & 23.3 & $268^{\ddagger}$ & $534^{*}$ & 48.6 \\
& SD & 12.0 & 201 & 329 & 12.1 \\
D160 & Mean & 23.2 & $641^{\S}$ & $899^{\S}$ & $73.6^{\S}$ \\
& SD & 12.4 & 478 & 700 & 5.8 \\
D200 & Mean & 22.9 & $724^{\mid 1}$ & $929^{\prime \prime}$ & $79.4^{\mid 14}$ \\
& SD & 12.4 & 552 & 727 & 5.4 \\
& & & & & \\
\hline
\end{tabular}

LVEDV, left ventricular end-diastolic volume, $\mathrm{ml}$; SW, stroke work, mmHg-ml; PVA, pressure-volume area, mmHg-ml; TranspVA, efficiency of energy transfer from PVA to SW, \%.

${ }^{*} P<0.004$ vs $C 120$.

$\ddagger P<0.002$ vs $\mathrm{C} 160$.

${ }^{\S} P<0.002$ vs $\mathrm{C} 160$.

" $P<0.002$ vs $C 200$.

$' P<0.02$ vs D160. ing dobutamine infusion $(P<0.002)$. After dobutamine infusion PVA was not reduced by increasing heart rate.

Transpva, reflecting the percentage of PVA transferred to the peripheral circulation as SW, was not affected by increased heart rate under control conditions. Trans PvA $_{\text {A }}$ was increased at both heart rates after the addition of dobutamine $(P<0.002)$. Also, Trans $\mathrm{PVA}_{\mathrm{A}}$ was increased further by increased heart rate after dobutamine infusion, from $73.6 \pm 5.8$ to $79.4 \pm 5.4 \%(P$ $<0.02$ ).

Effects of pacing and dobutamine on effective arterial elastance. Fig. 3 shows the $E_{\mathrm{a}}$ data under the five sets of test conditions. $E_{\mathrm{a}}$ increased from $14.2 \pm 4.5 \mathrm{mmHg} / \mathrm{ml}$ at C120 to $19.6 \pm 8.8$ and $24.2 \pm 10.4 \mathrm{mmHg} / \mathrm{ml}$ at $\mathrm{C} 160$ and $\mathrm{C} 200$ respectively $(P<0.25$ and $P<0.001)$. The addition of dobutamine reduced $E_{\mathrm{a}}$ at any heart rate. $E_{\mathrm{a}}$ at $\mathrm{D} 160$ was $16.0 \pm 8.1$ $\mathrm{mmHg} / \mathrm{ml}(P<0.025$ vs $\mathrm{Cl} 160)$, and was $17.7 \pm 7.3 \mathrm{mmHg} / \mathrm{ml}$ at D200 $(P<0.025$ vs $C 200)$. Of note, the value at D200 was not significantly higher than that at D160, indicating that dobutamine blunted the effect of increased rate on $E_{\mathrm{a}}$ seen under control conditions.

Fig. 4 shows the relation between $E_{\mathrm{a}}$ and Transpva. Under control conditions an increase in heart rate increased $E_{\mathrm{a}}$, with

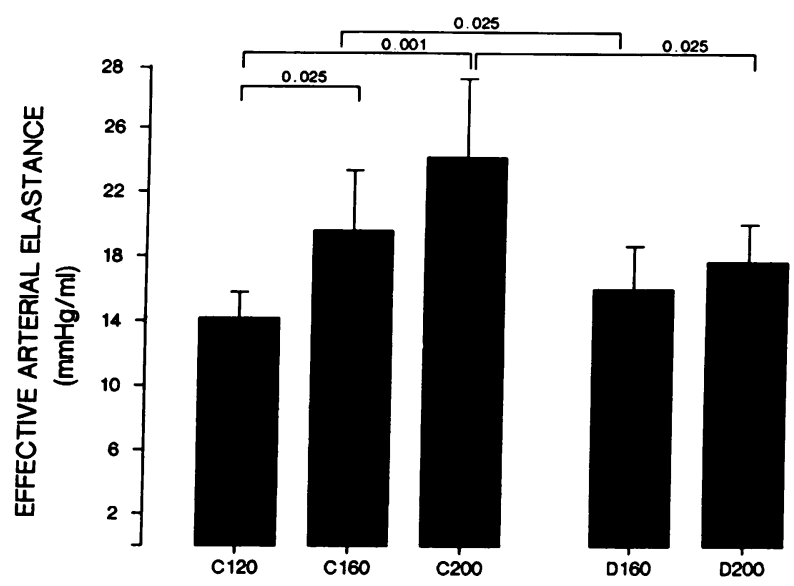

Figure 3. The effect of increases in heart rate before and after dobutamine on $E_{\mathrm{a}}$, the effective arterial elastance. The bars are 1 SEM. 


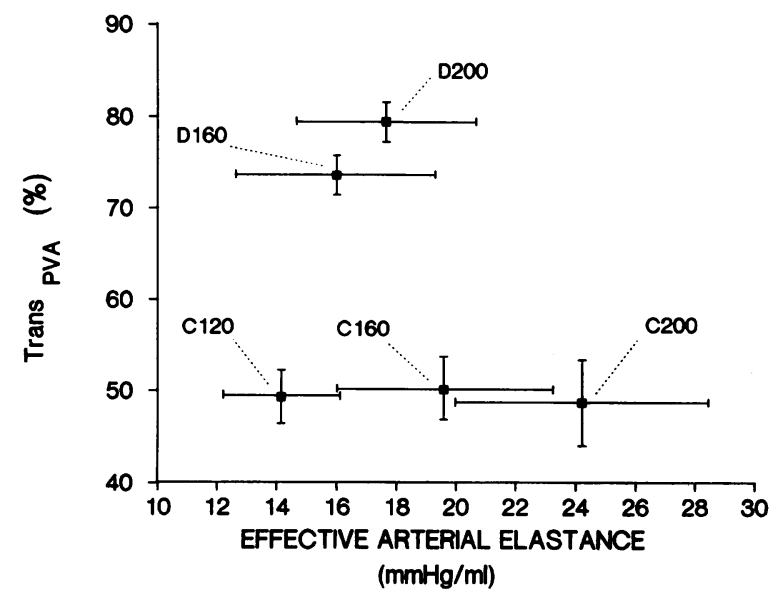

Figure 4. The relation of the percentage of pressure-volume area expressed as stroke work (Trans $\mathrm{PVA}_{\mathrm{A}}$ ) to effective arterial elastance under the five test conditions.

no substantial effect on Transpva. After the addition of dobutamine, however, $E_{\mathrm{a}}$ was lower at each heart rate, and Trans $\mathrm{PVA}_{\mathrm{P}}$ was markedly increased. Comparing Transpva at roughly equal $E_{\mathrm{a}}$ before and after dobutamine administration (C160 vs D200) it is seen that this inotropic agent markedly improves efficiency of energy transfer from PVA to SW, even when the effective arterial elastance is not substantially altered.

\section{Discussion}

The results of this study indicate that while both increased heart rate and dobutamine infusion increase myocardial contractility, they have substantially different effects on overall cardiovascular performance because of divergent effects on the vasculature. These two inotropic stimuli have different effects on arterial elastance and on the efficiency of energy transfer from PVA to SW. Thus, vascular properties play an important role in modulating how changes in contractility will be transmitted to the circulation.

As previously shown (6), increasing heart rate from 120 to $200 \mathrm{bpm}$ produces a moderate and incremental increase in

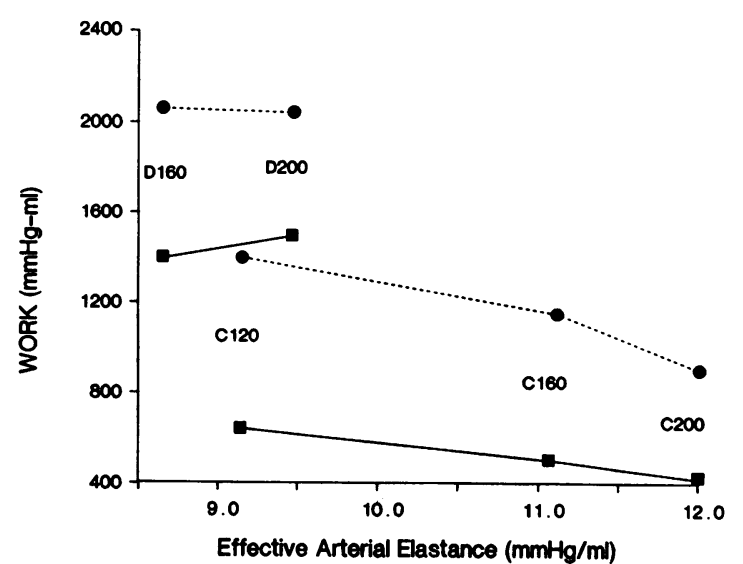

Figure 5. The response of stroke work (boxes) and pressure-volume area (circles) to the five test conditions in a typical animal. Control data are connected by solid lines and dobutamine data by the dashed lines. contractility, reflected by $E_{\mathrm{es}}$. In addition, increased heart rate causes an increase in the effective elastance of the systemic arterial bed, quantified as $E_{\mathrm{a}}$. The vascular response we measured is predicted by the model of Sunagawa et al. (20) in which $E_{\mathrm{a}}$ is inversely related to cardiac cycle length. $E_{\mathrm{a}}$, the ratio of end-systolic pressure $\left(P_{\mathrm{es}}\right)$ to stroke volume, depends not only on the material properties of the arterial system, but also on the arterial pressure when the aortic valve opens. During tachycardia, when the time for diastolic decay of the arterial pressure wave is shortened, the pressure at aortic valve opening will be higher, thus $P_{\mathrm{es}}$ and $E_{\mathrm{a}}$ will be increased.

Changes in the total peripheral resistance also affect $E_{\mathrm{a}}$ : if vascular resistance increases, so will $E_{\mathrm{a}}(20)$. Mangel et al. (21) have shown in rabbits that the aorta has rhythmic contractile activity, which is synchronized with the pulse pressure waves. They found that the aorta relaxes during the rise in pulse pressure, a response that would tend to reduce $E_{\mathrm{a}}$. It is possible that at heart rates markedly higher than those normally present in the animal this mechanism is saturated, and full relaxation does not occur. This could have added to the increase in $E_{\mathrm{a}}$ noted during rapid tachycardia in our experiments.

In contrast to the effect of heart rate on $E_{\mathrm{es}}$, another index of contractile performance, $M_{\mathrm{w}}$, was reduced at higher heart rates. Since $M_{\mathrm{w}}$ is based on stroke work, which may be sensitive to alterations in arterial properties of the magnitude seen in this study, the reduction of $M_{\mathrm{w}}$ concurrent with an elevation in $E_{\mathrm{a}}$ is not surprising.

How vascular changes determine if increased contractility will translate into improved overall cardiac performance can be seen by assessing the performance of the $\mathrm{LV}$ in terms of PVA and SW from a common LVEDV before and after increasing heart rate. Although contractility went up, both PVA and SW were decreased (Fig. 5). It is clear that the single beat mechanical output of the LV, expressed as either PVA or SW, is reduced when $E_{\mathrm{a}}$ is increased. Thus, increased heart rate is effective at eliciting the reserve of contractility available to the myocardium, but this is not fully transmitted to the circulatory bed due to concomitant vascular changes.

Dobutamine caused a marked increase in myocardial contractility, reflected by a greater than threefold increase in $E_{\text {es }}$ at matched heart rates. Dobutamine also led to lower effective arterial elastance, reducing $E_{\mathrm{a}}$ from $19.6 \pm 8.8 \mathrm{mmHg} / \mathrm{ml}$ at $\mathrm{C} 160$ to $16.0 \pm 8.1 \mathrm{mmHg} / \mathrm{ml}$ at $\mathrm{D} 160$. Additionally, after dobutamine infusion arterial elastance did not go up in response to increases in heart rate. In fact, rapid pacing after dobutamine infusion led to an increase in PVA and SW, not a decrease. Thus, in addition to increasing contractility, dobutamine has important effects on the vasculature which augment its effect on LV performance. These effects likely result from the known vasodilatory properties of this agent, which result from peripheral beta adrenergically mediated smooth muscle relaxation (22).

It is interesting that these two contractile stimuli appear to be additive. A body of data supports the notion that contractility is dependent on levels of free intracellular calcium (see 23 for review). During increases in heart rate this may in part result from augmented sodium-calcium exchange, not related to slow-channel-mediated calcium influx (24). Also, while action potential duration for each beat is shorter at faster rates, the total time spent in the depolarized phase per minute rises (25). Since this phase of the action potential corresponds to the 
influx of calcium via slow channels (26) it would in turn lead to increased $\left[\mathrm{Ca}^{2+}\right]_{i}$, and augmented contractility. Morgan and Blinks (27), using the photoprotein aequorin, have directly demonstrated an increase in the calcium transient of isolated cat papillary muscle segments during increased stimulation frequency.

The mechanisms by which $\left[\mathrm{Ca}^{2+}\right]_{\mathrm{i}}$ increases after catecholamine stimulation are related to both increased transsarcolemmal calcium movement and altered intracellular calcium handling. Catecholamine stimulation has been shown to increase intracellular cAMP, which leads to an increase in the number of slow calcium channels available for transsarcolemmal calcium transport during the slow action potential (28). cAMP also increases calcium triggered calcium release from the sarcoplasmic reticulum (29). We speculate that pacing during dobutamine infusion led to increased transsarcolemmal calcium movement by channel and nonchannel mediated pathways. These increments in calcium flux would heighten the increased calcium triggered calcium release due to dobutamine, hence the additive effect of increased frequency and dobutamine on contractility.

Our results must be viewed in the light of several potential limitations. The first is the assumption that the $P_{\text {es }}-V_{\text {es }}$ relation is linear. Burkhoff et al. (30) have shown in isolated hearts that the relation is curvilinear, and that the magnitude and direction of curvilinearity is dependent on contractile state. Little et al. (31), on the other hand, studied the same model used in this study, and showed a modest, but consistent level of curvilinearity of the relation over a wide range of contractile states. While the correlation coefficients of the linear regressions were high in every case in this study, extrapolation needed to determine PVA may entail some error. If the degree of curvilinearity is consistent, as shown by Little et al. (31), while our results may have consistently overestimated PVA and underesti-

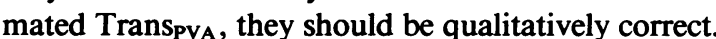

A second potential problem is the use of $E_{\mathrm{a}}$ from a single beat to assess the systemic vasculature. We used the first beat of each occlusion, since this beat is measured before substantial change in loading conditions occurs. While beats at various points in the caval occlusion were used to compare $\mathrm{d} P / \mathrm{d} t_{\max }$, PVA, and SW, use of $E_{\mathrm{a}}$ based on a single $\mathrm{LV}$ pressure-volume loop during caval occlusion (nonsteady state) may not accurately represent arterial elastance (20). We reasoned that steady state $E_{\mathrm{a}}$ provides a reasonable estimate of the arterial parameters and related it to the composite index of contractility, $E_{\text {es }}$, as well as to single beat estimates of $\mathrm{LV}$ performance during the caval occlusions. A more precise estimate of arterial elastance during individuaf beats may provide a more accurate way to evaluate instantaneous ventriculovascular coupling.

Finally, it should be pointed out that these studies were carried out after autonomic blockade with atropine and hexamethonium, and after anesthesia. While these data provide an insight into myocardial and vascular response to two inotropic stimuli, in conscious, autonomically intact animals further factors may play a role.

In summary, our data confirm that both increased heart rate and dobutamine lead to increased myocardial contractility, and that these stimuli are additive. How well this increase in contractility is transmitted to the circulatory bed is modulated by the response of the vasculature. Thus, ventriculovascular coupling plays an important role in determining the re- sponse of the heart to inotropic stimulation. An assessment of pump performance, reflective of the effects of such stimuli on both the heart and the vasculature will provide the best measure of their overall effect on cardiac function.

\section{Acknowledgments}

We thank Danny Escobedo and Don Watkins for technical assistance and John Schoolfield for statistical advice.

Supported by the Research Service of the Veterans Administration and the American Heart Association. Dr. Freeman is an Established Investigator of the American Heart Association.

\section{References}

1. Abbott, B. C., and W. F. H. M. Mommaerts. 1959. A study of inotropic mechanisms in the papillary muscle preparation. J. Gen. Physiol. 42:533-551.

2. Blinks, J. R., and J. Koch-Weser. 1961. Analysis of the effects of changes in rate and rhythm upon myocardial contractility. J. Pharmacol. Exp. Ther. 134:373-389.

3. Sonnenblick, E. H. 1962. Force-velocity relations in mammalian heart muscle. Am. J. Physiol. 202:931-939.

4. Mitchell, J. H., A. G. Wallace, and N. S. Skinner, Jr. 1963. Intrinsic effects of heart rate on left ventricular performance. Am. J. Physiol. 205:41-48.

5. Covell, J. W., J. Ross, Jr., R. Taylor, E. H. Sonnenblick, and E. Braunwald. 1967. Effects of increasing frequency of contraction on the force velocity relation of left ventricle. Cardiovasc. Res. 1:2-8.

6. Freeman, G. L., W. C. Little, and R. A. O'Rourke. 1987. Influence of heart rate on left ventricular performance in conscious dogs. Circ. Res. 61:455-464.

7. Sagawa, K., L. Maughan, H. Suga, and K. Sunagawa. 1988. Cardiac Contraction and the Pressure-Volume Relationship. Oxford University Press Inc., New York.

8. Glower, D. D., J. A. Spratt, N. D. Snow, J. S. Kabas, J. W. Davis, C. O. Olsen, G. S. Tyson, D. C. Sabiston, Jr., and J. S. Rankin. 1985. Linearity of the Frank-Starling relationship in the intact heart: the concept of preload recruitable stroke work. Circulation. 71:994-1009.

9. Freeman, G. L., and J. T. Colston. 1989. Evaluation of long-term variance of left ventricular performance indexes in closed-chest dogs. Am. J. Physiol. (Heart. Circ. Physiol. 26):H70-H78.

10. Suga, H., T. Hayashi, M. Shirahata, and I. Ninomiya. 1980. Critical evaluation of left ventricular systolic pressure volume area as predictor of oxygen consumption rate. Jpn. J. Physiol. 30:907-919.

11. Suga, H., T. Hayashi, M. Shirahata, S. Suehiro, and R. Hisano. 1981. Regression of cardiac oxygen consumption on ventricular pressure-volume area in dog. Am. J. Physiol. 240:H320-H325.

12. Nozawa, T., Y. Yasumura, S. Futaki, N. Tanaka, M. Uenishi, and H. Suga. 1988. Efficiency of energy transfer from pressure-volume area to external mechanical work increases with contractile state and decreases with afterload in the left ventricle of the anesthetized closedchest dog. Circulation. 77:1116-1124.

13. Sunagawa, K., W. L. Maughan, D. Burkhoff, and K. Sagawa. 1983. Left ventricular interaction with arterial load studied in isolated canine ventricle. Am. J. Physiol. 245:H733-H780.

14. Sunagawa, K., W. L. Maughan, and K. Sagawa. 1985. Optimal arterial resistance for the maximal stroke work studied in isolated canine left ventricle. Circ. Res. 56:586-595.

15. Guide for the Care and Use of Laboratory Animals. 1985. U.S. Department of Health and Human Services, NIH Publication No. 86-23.

16. Sodums, M. T., F. R. Badke, M. R. Starling, W. C. Little, and R. A. O'Rourke. 1984. Evaluation of left ventricular contractile performance utilizing end-systolic pressure-volume relationships in conscious dogs. Circ. Res. 54:731-739. 
17. Freeman, G. L., D. Watkins, and W. C. Little. A simple method of measurement of left ventricular septal-lateral dimension. Am. J. Physiol. 254:H801-H803.

18. Kono, A., W. L. Maughan, K. Sunagawa, K. Hamilton, K. Sagawa, and M. L. Weisfeldt. 1984. The use of left ventricular endejection pressure and peak pressure in the estimation of the end-systolic pressure-volume relationship. Circulation. 70:1057-1065.

19. Little, W. C. 1985. The left ventricular $\mathrm{dP} / \mathrm{dt}_{\max }$-end-diastolic volume relation in closed-chest dogs. Circe. Res. 56:808-815.

20. Sunagawa, K., K. Sagawa, and W. L. Maughan. 1984. Ventricuar interaction with the loading system. Ann. Biome. Eng. 12:163189.

21. Mangel, A., M. Fahim, and C. van Breemen. 1981. Rhythmic contractile activity of the in vive rabbit aorta. Nature (Lond.). 289:692-694.

22. Ruffolo, R. R., Jr. 1987. Review: the pharmacology of dobutamine. Am. J. Med. Sci. 294:244-248.

23. Ruegg, J. C. 1987. Calcium in Muscle Activation. SpringerVerlag New York, Inc., New York. 300 pp.

24. She, S., V. K. Sharma, and A. Uglesity. 1986. $\mathrm{Na}^{+}-\mathrm{Ca}^{2+}$ exchange contributes to increase of cytosolic $\mathrm{Ca}^{2+}$ concentration during depolarization in heart muscle. Am. J. Physiol. 250:C651-C656.
25. Pigeon, J., M. Lab, A. Seed, G. Elzinga, D. Papadoyannis, and M. I. M. Noble. 1980. The contractile state of cat and dog heart in relation to the interval between beats. Circe. Res. 47:559-567.

26. Sperelakis, N. 1984. The slow action potential and properties of the myocardial slow channels. In Physiology and Pathophysiology of the Heart. N. Sperelakis, editor. Martinus Nijhoff Publishing, Boston. 159-186.

27. Morgan, J. P., and J. R. Blinks. 1982. Intracellular calcium ${ }^{2+}$ transients in the cat papillary muscle. Can. J. Physiol. Pharmacol. 60:524-528.

28. Brum, G., W. Osterrieder, and W. Trautwein. 1984. $\beta$-adreneric increase in the calcium conductance of cardiac myocytes studied with the patch clamp. Pfluegers Arch. Eur. J. Physiol. 401:111-118.

29. Kranias, E. G., and J. Solano. 1983. Coordination of cardiac sarcoplasmic reticulum and myofibrillar function by protein posphorylation. Fed. Proc. 42:33-38.

30. Burkhoff, D., S. Sugiura, D. T. Yue, and K. Sagawa. 1987. Contractility-dependent curvilinearity of end-systolic pressure-volume relations. Am. J. Physiol. 252:H1218-H1227.

31. Little, W. C., C. P. Chang, T. Peterson, and J. Vinten-Johansen. 1988. Response of the left ventricular end-systolic pressure-volume relation in conscious dogs to a wide range of contractile states. $\mathrm{CirCu}$ lation. 78:736-745.

1284

G. L. Freeman and J. T. Colston 